\title{
Influence of trans-polyoctylene rubber content on styrene-butadiene rubber properties
}

\author{
Patrik Macúrika $^{a}$ Rafal Anyszka ${ }^{\text {b, c }}$, Ivan Hudec ${ }^{a}$, \\ Terézia Malčekováa ${ }^{a}$ Ján Kruželák ${ }^{a}$ \\ ${ }^{a}$ Department of Plastics, Rubber and Fibres, Slovak University of Technology in Bratislava, \\ Radlinského 9, 81237 Bratislava, Slovakia \\ ${ }^{b}$ Chair of Elastomer Technology and Engineering, University of Twente, \\ De Horst 2, 7522 LW Enschede, The Netherlands \\ 'Institute of Polymer and Dye Technology, Lodz University of Technology, \\ Stefanowskiego 12/16, 90-924 Łódź, Poland \\ patrik.macurik@stuba.sk
}

\begin{abstract}
The study was focused on the investigation of trans-polyoctylene (TOR) influence on cross-linking as well as mechanical and rheological properties of rubber compounds based on styrene-butadiene rubber (SBR). SBR was compounded with different proportions of TOR in the concentration range from 0 to $30 \mathrm{phr}$. Integration of TOR into rubber leads to the prolongation of the optimum curing time and scorch time and thus the decrease of the curing rate. Higher content of TOR led to less viscous rubber due to the plasticizing effect. Cross-link density of vulcanizates was reduced, which correlates with higher elongation at break. Tensile strength and hardness of vulcanizates increased with the increasing TOR content, probably due to the increasing amount of the crystalline phase.
\end{abstract}

Keywords: trans-polyoctylene rubber, styrene-butadiene rubber

\section{Introduction}

Styrene-butadiene rubber is the most widely used and very important synthetic rubber worldwide. It has entered the market due to its low cost, use in automotive industry (good abrasion resistance) and high level of product uniformity (Niyogi, 2007). SBR is nonpolar rubber with good mechanical characteristics. In comparison with natural rubber, it has better oxygen and ozone resistance and good abrasion resistance (Noriman et al., 2010). SBR is used in a wide range of applications such as automotive tire sidewalls, cover strips, wires, cables, footwear, roofing barriers and sporting goods (Zhou et al., 2010). Vestenamer is produced by ring-opening metathesis polymerization (ROMP) from cyclooctene and it is known as trans-polyoctene rubber (TOR) consisting of unbranched linear and cyclic macromolecules which contain one double bond for every eighth carbon atom with prevalently trans isomeric double bonds. TOR is a semicrystalline rubber known as a compatibilizer for incompatible blends as well as a processing aid. It can provide good processability in the temperature range of rubber processing $\left(100-150{ }^{\circ} \mathrm{C}\right)$ as well as good collapse resistance below the melting temperature $\left(54^{\circ} \mathrm{C}\right.$ ) due to recrystallization (Awang et al., 2007; Evonik website, 2019). It is a high-performance polymer with dual character. During rubber processing, blends play the role of plasticizers and in process of vulcanization they react as unsaturated rubber. Due to this dual character, processing of natural rubber/styrene-butadiene rubber blend is improved in terms of energy savings and handling of intermediary compounds and the vulcanization profile is changed. TOR as unsaturated rubber can enable cross-linking with sulfur, sulfur donors, peroxides or cure resins (Pana at al., 2008; Nah, 2002; Noriman et al., 2012; Chang et al., 1999).

\section{Material and methods}

As the rubber matrix, a solution of polymerized styrene-butadiene rubber containing $25 \%$ of styrene (Arlanxeo, Germany) was used. Trans-polyoctylene rubber (TOR), trademark Vestenamer 8012 (Evonik, Germany), was dosed to the rubber matrix as an additive in the concentration range from $0 \mathrm{phr}$ to $30 \mathrm{phr}$ (weight parts of TOR per hundred weight parts of rubber). Compounds contained standard semi EV sulfur curing system consisting of zinc oxide $-3 \mathrm{phr}$ (Slovzink, Košeca, Slovakia) and stearic acid $-2 \mathrm{phr}$ (Setuza, Ústí nad Labem, Czech republic) as activators, N-cyclohexyl-2-benzothiazole sulfonamide CBS - $1.5 \mathrm{phr}$ (Duslo, Šala, Slovakia) as accelerator, and sulfur - 1.5 phr (Siarkopol, Tarnobrzeg, Poland) as curing agent.

\section{Preparation and curing of rubber compounds}

The two-step mixing of rubber compounds was carried out in a laboratory mixer Brabender. Rubber, zinc oxide and stearic acid were compounded in the 
first step $\left(9\right.$ minutes, $\left.90^{\circ} \mathrm{C}\right)$, whereas the curing system (CBS and sulfur) was introduced in the second step $\left(4\right.$ minutes, $90{ }^{\circ} \mathrm{C}$ ). After that, the blends were homogenized in a two roll mill. One reference and six samples with different content of TOR additive (5; 10; 15; 20; 25; 30 phr) were prepared. Curing characteristics of the rubber compounds were investigated from the corresponding curing isotherms measured by a MDR rheometer at $160{ }^{\circ} \mathrm{C}$. The curing process was performed at $160{ }^{\circ} \mathrm{C}$ for the optimum curing time calculated from the curing isotherms under the pressure of $15 \mathrm{MPa}$ using a hydraulic press (Fontijne, N.V. Machinefabriek, Vlaardingen, The Netherlands). Finally, thin sheets $(150 \times 150 \mathrm{~mm}$, thickness of $2 \mathrm{~mm})$ of cured rubber were obtained.

Determination of cross-link density of rubber blends Cross-link density, $\nu$, was determined based on equilibrium swelling of the samples in o-xylene. First, the samples were swelled in o-xylene until equilibrium swelling was reached. The cross-link density was then calculated based on the equilibrium swelling degree by applying the Flory-Rehner equation (1) (Noriman et al., 2012):

$$
\nu=-\frac{\ln \left(1-V_{r}\right)+V_{r}+\chi V_{r}^{2}}{V_{s}\left(V_{r}^{1 / 3}-0,5 V_{r}\right)}
$$

where $v-$ is the cross-link density $\left(\mathrm{mol} / \mathrm{cm}^{3}\right), V_{r}-$ volume fraction of rubber in equilibrium swelling sample of a vulcanizate, $V_{s}$ - molar volume of solvent (123.45 $\mathrm{cm}^{3} / \mathrm{mol}$ for o-xylene), $\chi-$ Huggins interaction parameter $(0.4106$ in this case).

\section{Evaluation of physical-mechanical properties}

Tensile properties of the tested cured rubber compounds were measured using a Zwick Roell/Z 2.5, (Ulm, Germany) tester operating at the crosshead speed of $500 \mathrm{~mm} / \mathrm{min}$ and room temperature in accordance with the valid technical standards. Testing was performed with dumbbell-shaped test specimens (width of $6.4 \mathrm{~mm}$, length of $80 \mathrm{~mm}$, and thickness of $2 \mathrm{~mm}$ ). Hardness was measured using a durometer (HW WALLACE and CO LTD CROYDON CR9 2HR) and the unit was expressed in IRHD (International Rubber Hardness Degree).

\section{Determination of rheological properties - complex viscosity}

Rheological properties of the samples were determined by an oscillating rheometer RPA 2000 in accordance with ISO 13145 standard for rubber mixtures. Torque was measured over time at constant oscillation deflection and the oscillation frequency of the oscillating cone at $80^{\circ} \mathrm{C}$. The sam- ples were placed between thick polymer film layers. The measurements were performed in shear mode in a closed chamber and the results are in form of flow curves characterized by shear rate, $\dot{\gamma}\left[\mathrm{s}^{-1}\right]$, and complex viscosity, $\eta^{*}[\mathrm{~Pa} \mathrm{~s}]$.

\section{Differential scanning calorimetry}

Differential scanning calorimetry measurements were performed under nitrogen atmosphere at the heating/cooling rate of $10{ }^{\circ} \mathrm{C} / \mathrm{min}$ using a Mettler-Toledo Inc apparatus and the "SW STARe" software. The samples were placed in standard aluminum pans with pierced lids. Heating and cooling programs were performed as follows: the sample was heated from $25^{\circ} \mathrm{C}$ to $200{ }^{\circ} \mathrm{C}$, cooled from $200{ }^{\circ} \mathrm{C}$ to $-65^{\circ} \mathrm{C}$ and again heated to $200^{\circ} \mathrm{C}$.

\section{Results and discussion}

\section{Influence of TOR on curing process and cross-link density}

Fig. 1 shows the curing characteristics of SBR/TOR rubber compounds. As it is shown, optimum curing time, $\mathrm{t}_{90}$, and scorch time, $\mathrm{t}_{\mathrm{s} 1}$, were prolonged with the increasing content of TOR, which suggests that TOR influences the cross-linking process of rubber compounds. TOR contains a double bond at every eighth carbon atom, which is why the curing rate was lower in comparison with unmodified SBR blends.

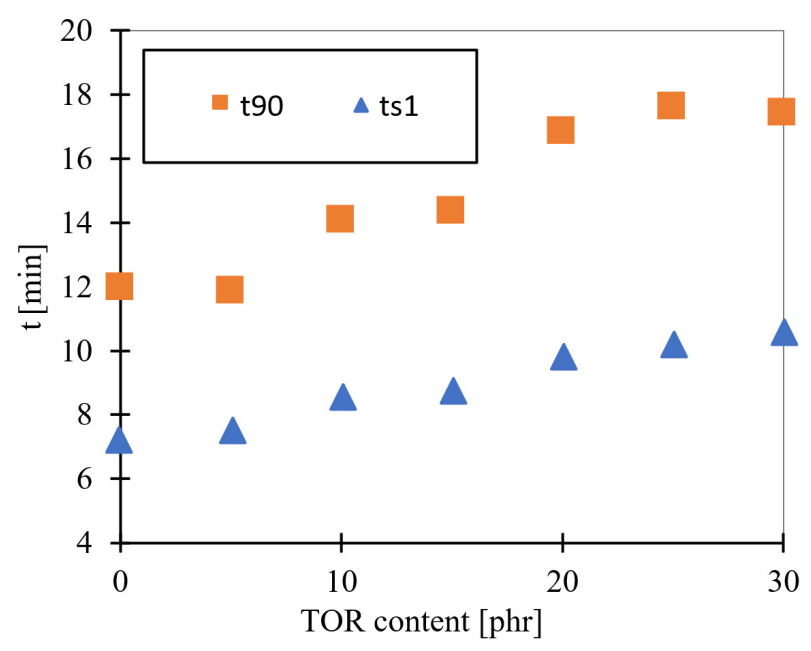

Fig. 1. Influence of TOR content on optimum curing time, $\mathrm{t}_{90}$, and scorch time, $\mathrm{t}_{\mathrm{s} 1}$, of rubber compounds.

Minimum torque, $\mathrm{M}_{\mathrm{L}}$, and maximum torque, $\mathrm{M}_{\mathrm{H}}$, values are listed in Table 1; they decrease with the increasing TOR content. This can be attributed to the decrease in the cross-linking density of vulcanizates (Fig. 2) and of the viscosity of rubber compounds 
with the increasing amount of TOR. Usually, a correlation between the torque difference (difference between the maximum and the minimum torque) and the cross-linking density is observed. This means that with the decreasing cross-linking density, the torque difference also decreases. Similarly, lower viscosity of rubber compounds shifts the torque difference to lower values. The results obtained from the determination of cross-linking density (Fig. 2) and complex viscosity (Fig. 3) confirmed the presumption of both parameters decrease proportional to the amount of TOR. A possible explanation of the cross-linking density decrease can be the curable character of TOR added without increasing the sulfur and CBS content. Therefore, each sample containing a higher amount of TOR contained relatively lower amounts of sulfur and CBS for curing. Higher number of curable macromolecules decreased the cross-linking density.

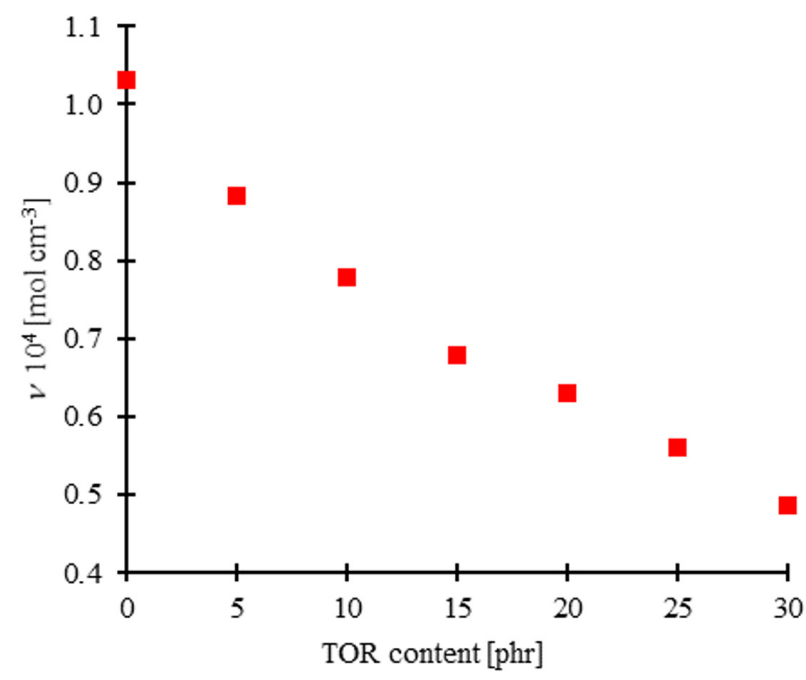

Fig. 2. Influence of TOR content on cross-linking density, $\nu$, of vulcanizates.

\section{Influence of TOR on complex viscosity of rubber compounds}

In Fig. 3, the pseudoplastic behavior of tested rubber compounds was confirmed. When higher shear rate was applied, lower complex viscosity was reached. Plasticizer effect of TOR is acknowledged because lower viscosity of rubber compounds was achieved with the increasing content of TOR. When comparing individual complex viscosities (Fig. 4) for one shear rate (10 Pa s), it can be clearly seen that a higher amount of TOR can improve the processability of rubber compounds by reducing the complex viscosity (Fig. 4).

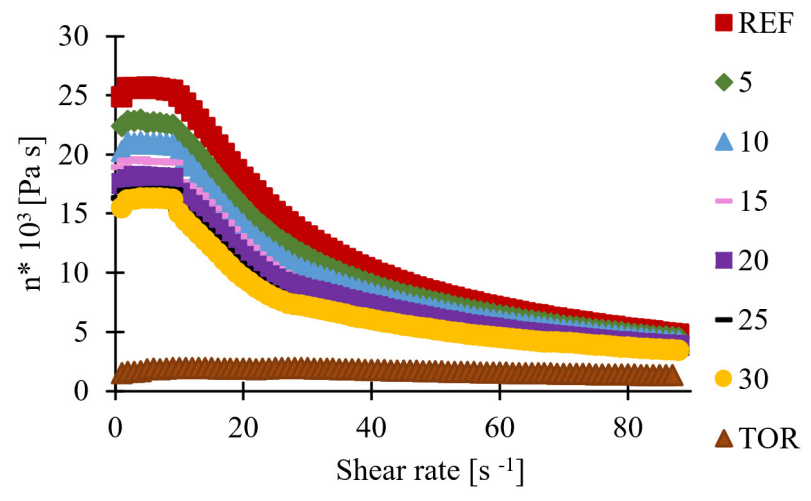

Fig. 3. Debendence of complex viscosity, $\eta^{*}$, on shear rate, $\dot{\gamma}$, of rubber compounds with different content of TOR [phr].

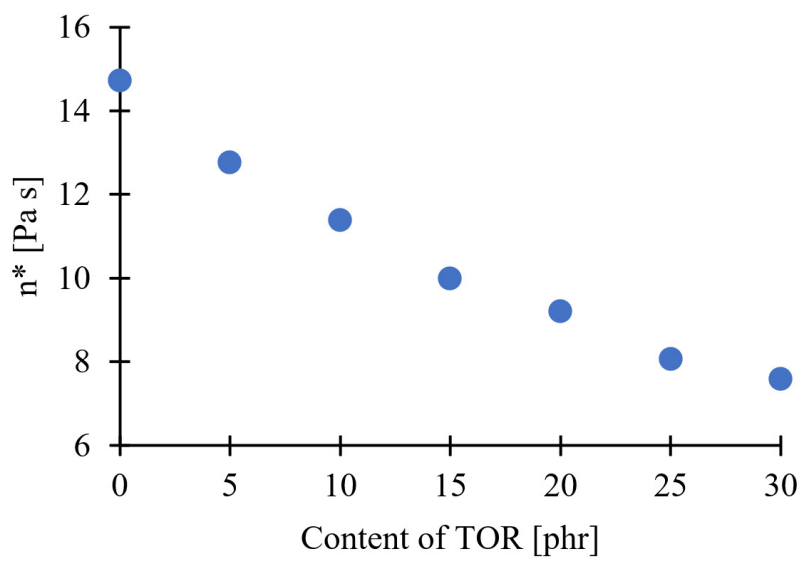

Fig. 4. Dependence of complex viscosity on TOR content at the shear rate of $10 \mathrm{~s}^{-1}$.

Influence of TOR on physical-mechanical properties Mechanical properties of vulcanizates are illustrated in Figs. 5 and 6. It becomes obvious that

Tab. 1. $\mathrm{M}_{\mathrm{L}}$ (minimum torque) and $\mathrm{M}_{\mathrm{H}}$ (maximum torque) of SBR/TOR blends.

\begin{tabular}{lccccccc}
\hline $\begin{array}{l}\text { TOR content } \\
{[\mathbf{p h r}]}\end{array}$ & $\mathbf{0}$ & $\mathbf{5}$ & $\mathbf{1 0}$ & $\mathbf{1 5}$ & $\mathbf{2 0}$ & $\mathbf{2 5}$ & $\mathbf{3 0}$ \\
\hline $\begin{array}{l}\mathbf{M}_{\mathbf{L}} \\
{[\mathbf{d N ~} \mathbf{m}]}\end{array}$ & 0.63 & 0.60 & 0.57 & 0.54 & 0.51 & 0.48 & 0.46 \\
\hline $\begin{array}{l}\mathbf{M}_{\mathbf{H}} \\
{[\mathbf{d N ~} \mathbf{m}]}\end{array}$ & 10.89 & 10.54 & 10.70 & 9.96 & 9.75 & 9.36 & 9.21 \\
\hline $\begin{array}{l}\Delta \mathbf{M} \\
{[\mathbf{d N ~} \mathbf{m}]}\end{array}$ & 10.26 & 9.94 & 10.13 & 9.42 & 9.24 & 8.88 & 8.75 \\
\hline
\end{tabular}


increasing the TOR content has positive influence on the tensile strength and hardness (Fig. 5). In the vulcanized compounds, crystalline transpolyoctenylenes, such as TOR, are supposed to have a certain reinforcing effect on the vulcanizates. As a result, the hardness and the tensile properties of the vulcanizates increased (Kraus, 1963). The increase of elongation at break was also recorded, which can be attributed to the decrease of cross-link density of vulcanizates with the increasing amount of TOR (Fig. 6). Higher cross-link density leads to higher rubber chains mobility and lower elasticity. Also, mechanical properties of vulcanizates are positively influenced by TOR addition contributing thus, together with the improved processability, to the preparation of vulcanizates with higher tensile strength and elongation at break.

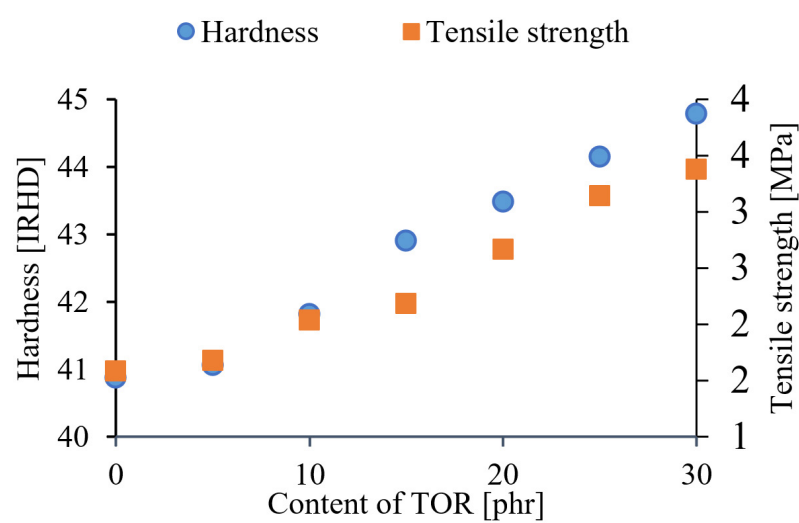

Fig. 5. Influence of TOR content on tensile strength and hardness of SBR/TOR vulcanizates.

- Crosslinking density Elongation at break

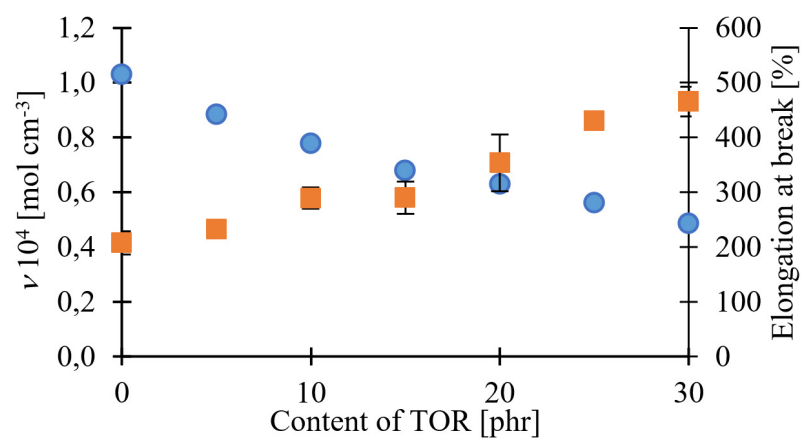

Fig. 6. Correlation between cross-linking density, $\nu$, and elongation at break of vulcanizates.

\section{Differential scanning calorimetry}

SBR is an amorphous type of rubber while TOR is a semicrystalline polymer with a $35 \%$ crystallinity. High proportion of the crystalline phase influences the properties of vulcanizates due to its reinforcing effect (Figs. 7, 8). In general, increasing the amount of the crystalline phase increases the reinforcing effect of vulcanizates (Bhowmick, 2001).

Tab. 2. Thermal properties (change of crystallization entalphy, $\Delta \mathrm{H}$, melting temperature, $\mathrm{T}_{\mathrm{m}}$, and crystallization temperature, $\mathrm{T}_{\mathrm{c}}$ ) of SBR compounds with different content of TOR [phr].

\begin{tabular}{lcccc}
\hline Blend & TOR & $\begin{array}{c}\text { SBR } \\
\text { TOR } \\
\mathbf{3 0}\end{array}$ & $\begin{array}{c}\text { SBR } \\
\text { TOR } \\
\mathbf{2 0}\end{array}$ & $\begin{array}{c}\text { SBR } \\
\text { TOR } \\
\mathbf{1 0}\end{array}$ \\
\hline $\begin{array}{l}\Delta \mathbf{H}[\mathbf{J} / \mathbf{g}] \\
\text { melting }\end{array}$ & 53.7 & 7.7 & 4.0 & 2.2 \\
\hline $\begin{array}{l}\mathbf{T}_{\mathbf{m}}\left[{ }^{\circ} \mathbf{C}\right] \\
\text { (onset) }\end{array}$ & 50.0 & 34.3 & 39.6 & 37.3 \\
\hline $\begin{array}{l}\mathbf{T}_{\mathbf{m}}\left[{ }^{\circ} \mathbf{C}\right] \\
\text { (peak) }\end{array}$ & 65.2 & 50.6 & 50.2 & 48.9 \\
\hline $\begin{array}{l}\mathbf{\Delta} \mathbf{H}[\mathbf{J} / \mathbf{g}] \\
\mathbf{c o o l i n g}\end{array}$ & -33.7 & -2.7 & -0.4 & -0.2 \\
\hline $\begin{array}{l}\mathbf{T}_{\mathbf{c}}\left[{ }^{\circ} \mathbf{C}\right] \\
(\text { onset) }\end{array}$ & 34.8 & 28.1 & 27.4 & 25.8 \\
\hline $\begin{array}{l}\mathbf{T}_{\mathbf{c}}\left[{ }^{\circ} \mathbf{C}\right] \\
\text { (peak) }\end{array}$ & 29.4 & 23.4 & 22.2 & 22.0 \\
\hline
\end{tabular}

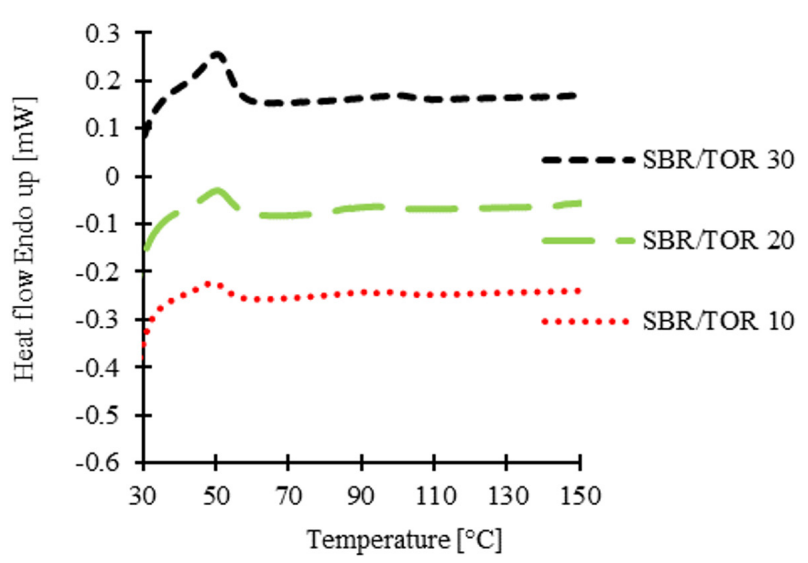

Fig. 7. DSC curve for SBR/TOR rubber compounds with different TOR content (heating).

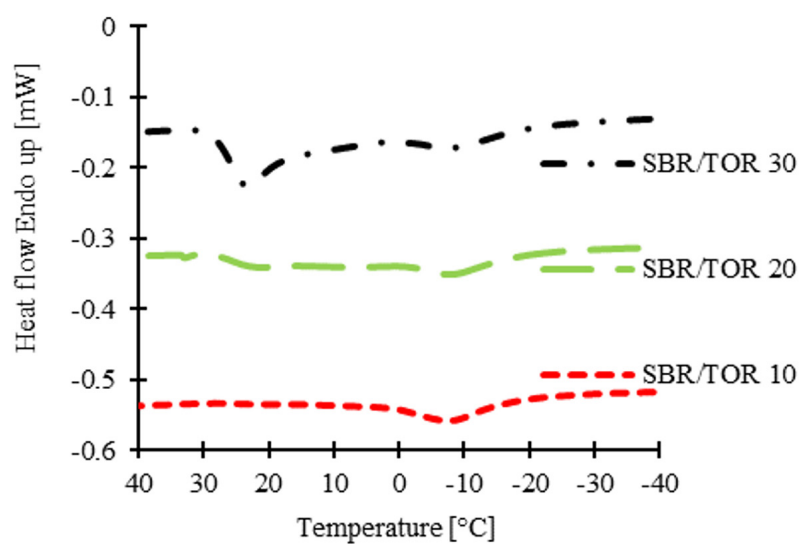

Fig. 8. DSC curve for SBR/TOR rubber compounds with different TOR content (cooling). 


\section{Conclusion}

The goal of this work was to investigate the influence of TOR on the properties of prepared SBR/ TOR rubber. The presence of TOR caused a decrease in the vulcanization rate and thus an increase in the optimal curing time and scorch time. The modified rubber had a pseudoplastic character. Increasing content of TOR reduced the complex viscosity. The tensile strength and hardness increased with the TOR addition as the increasing amount of TOR leads to the increasing amount of the crystalline phase in vulcanizates. The elongation at break of vulcanizates also increased with the increasing amount of TOR as a result of the decrease in the cross-link density. TOR increased also the melting point and crystallization temperature of SBR blends. Residual crystalline phase was presented proportionally with the increasing amount of TOR.

\section{Acknowledgement}

This work was supported by the Slovak Research and Development Agency under the contract No. APVV-0694-12.

\section{References}

Awang M, Ismail H, Hazizan MA (2007) Polypropylenebased blends containing waste tire dust: Effects of trans-polyoctylene rubber (TOR) and dynamic vulcanization. Polymer testing, 26: 779-787.
Bhowmick AK, Stephens HL (2001) In: Handbook of elastomers, second edition (p 710), CRC press, New York.

Evonik official website (2020) https://www.vestenamer. $\mathrm{com} /$ product/vestenamer/en/Pages/vestenamer. aspx.

Chang YW, Shin YS, Chun H, Nah C (1999) Effects of trans-polyoctylene rubber (TOR) on the properties of NR/EPDM blends, J Appl Polym Sci, 73, 5: $749-756$.

Kraus G (1963) J. Appl. Polym. Sci. 7: 861-871.

Nah C (2002) Effects of trans-polyoctylene rubber on rheological and green tensile properties of natural rubber/acrylonitrile-butadiene rubber blends, Polym Int 51: 245.

Niyogi KU (2007) In: Introduction to fibre science and rubber technology (p. 11-14), Shri Ram institute for industrial research, Delphi.

Noriman NZ, Ismail H, Rashid AA (2010) Characterization of styrene butadiene rubber/recycled acrylonitrile-butadiene rubber (SBR/NBRr) blends: The effects of epoxidized natural rubber (ENR-50) as a compatibilizer.

Noriman NZ, Ismail H, Rashid AA (2012) Properties of styrene butadiene rubber/recycled acrylonitrilebutadiene rubber (SBR/NBRr) blends: Effect of the addition of trans-polyoctylene rubber, J Appl Polym Sci, 126, S2, E56-E63.

Pena BCM, DemarquetteNR, Effect of the processing conditions and the addition of trans-polyoctenylene rubber on the properties of natural rubber/ styrene-butadiene rubber blends, J Appl Polym Sci 109: 445-451.

Zhou XW, Zhu YF, Liang J, Yu SY (2010) New fabrication and mechanical properties of styrene butadiene rubber/carbon nanotubes nanocomposite, J. Mater. Sci. Technol., 26(12): 1127-1132. 